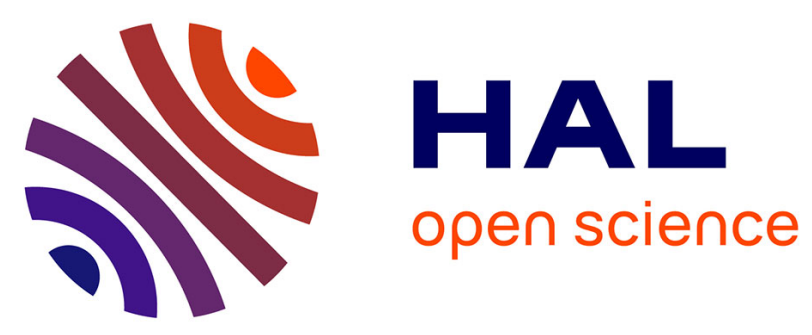

\title{
MELTING AND FREEZING KINETICS INDUCED BY PULSED ELECTRON BEAM ANNEALING IN ION-IMPLANTED SILICON
}

G. Chemisky, Damien Barbier, A. Laugier

\section{- To cite this version:}

G. Chemisky, Damien Barbier, A. Laugier. MELTING AND FREEZING KINETICS INDUCED BY PULSED ELECTRON BEAM ANNEALING IN ION-IMPLANTED SILICON. Journal de Physique Colloques, 1983, 44 (C5), pp.C5-91-C5-95. 10.1051/jphyscol:1983515 . jpa-00223095

\section{HAL Id: jpa-00223095 https://hal.science/jpa-00223095}

Submitted on 1 Jan 1983

HAL is a multi-disciplinary open access archive for the deposit and dissemination of scientific research documents, whether they are published or not. The documents may come from teaching and research institutions in France or abroad, or from public or private research centers.
L'archive ouverte pluridisciplinaire HAL, est destinée au dépôt et à la diffusion de documents scientifiques de niveau recherche, publiés ou non, émanant des établissements d'enseignement et de recherche français ou étrangers, des laboratoires publics ou privés. 


\author{
G. Chemisky, D. Barbier and A. Laugier \\ Laboratoire de Physique de Za Matière (LA 358), Institut National des Sciences \\ Appliquées de Lyon, 20, avenue Albert Einstein, 69621 Villeurbanne Cedex, \\ Eronce
}

\title{
RESUME
}

Les mécanismes d'interaction faisceau d'énergie-matériau déterminent les phénomènes de recristallisation par épitaxie liquide. Dans ce travail, nous avons simulé, pour un faisceau d'électrons polycinétique pulsé, les cinétiques de recristallisation de silicium implanté. Nous avons étudié l'influence du spectre d'électrons (12 et $15 \mathrm{keV}$ d'énergie moyenne), de l'énergie superficielle $\left(0,7\right.$ à $1,4 \mathrm{~J} / \mathrm{cm}^{2}$ ) sur ces cinétiques pour deux températures initiales (20 et $\left.450^{\circ} \mathrm{C}\right)$.

Après irradiation, l'enthalpie dans la zone portée à la température de fusion n'est pas uniformément distribuée. La vitesse de recristallisation dépend principalement du gradient thermique post-zone fondue.

L'effet du préchauffage à $450^{\circ} \mathrm{C}$ diminue la vitesse de recristallisation et allonge considérablement le temps de séjour à haute température de la couche superficielle.

\section{ABSTRACT}

Annealing effects of a pulsed energy beam in the liquid phase epitaxy regime mostly depend on beam material interaction mechanism. In this work the melting and freezing kinetics induced by a polykinetic electron beam pulse in ion-implanted silicon have been simulated for different electron beam parameters (energy spectrum and fluence) and two starting temperature 20 and $450^{\circ} \mathrm{C}$.

The enthalpy absorbed in the melting layer is not uniformly distributed so that the front surface is turned into melt within the pulse duration while the melting layer back end remains partially molten.

The melting-solid interface mostly depends on the thermal gradients in the solid beneath the melting layer and the latent heat fraction to be evacuated in the bulk of the material.

The effect of amorphous layer thickness was also invistigated.

Pulsedelectron beam annealing on $450^{\circ} \mathrm{C}$ heated silicon produces an increase of the fully molten layer thickness and a noticable decrease of the melting-solid interface velocity by the same factor as the thermal gradient inside the solid region. Consequently, heat release from the surface is slowed down so that after resolidification the silicon surface temperature stays higher than $800^{\circ} \mathrm{C}$ a longer time.

\section{INTRODUCTION}

Ion implantation followed by a submicrosecond energy pulse (laser or electron) is now considered as a very attractive doping process either for the microelectronics or for the solar cells industry $/ 1,2 \%$.

It has been demonstrated that short duration pulsed electron beam can be used to remove implantation damage in silicon by liquid phase epitaxial regrowth of the ion implanted surface layer starting from the defect free underlying crystal./3/. 
Thermal effects such as enthalpy deposition profile, maximum layer thickness, liquid phase duration and meit front velocity are determined by both the beam energy deposition profile and surface crystal structure.

In this paper, the computer simulation of the Pulsed Electron Beam Annealing (PEBA) induced thermal effects have been performed. The particular features of PEBA induced melting and freezing kinetics are investigated as a function of the substrate starting temperature $\left(20^{\circ} \mathrm{C}\right.$ or $450^{\circ} \mathrm{C}$ ) and the amor phous layer thickness.

Experimental data are extracted from the monitoring system of a broad beam SPIRE 300 pulsed electron beam processor. This machine mostly designed for research applications produces polykinetic electron pulses of $50 \mathrm{~ns}$ in duration over a few square centimeters area. The pulse is obtained by discharge of a capacitor in a vacuum plasma field emission diode. $A$ full description of the apparatus is given in ref./4/. The time-dependent electron energy deposition profile is computed starting from direct measurement of the diode current and voltage-waveforms during each shot.

In this work, the mean electron energy have been varied from 10 to $20 \mathrm{keV}$ with fluences independently ranging from 0.7 to $1.4 \mathrm{~J} / \mathrm{cm}^{2}$.

\section{COMPUTER STIMULATION OF THE TEMPERATURE PROFILES}

Valuable simulation results are obtained with any thermal model only if the beam interaction mechanisms with the material are well known.

In the case of electrons, the interaction mechanisms are nearly temperature and crystal structure independent. Moreover for incident electron energies less than $150 \mathrm{keV}$ only thermal relaxation processes occur. In a previous work $/ 5 /$, Monte-Carlo simulation has been used to determine the normalized electron energy loss functions in silicon for various values of the incidence angle. The heat generation function $\phi(x, t)$ of a polykinetic electron beam pulse can thus be precisely established. At any time after the beginning of the pulse the depth-temperature profiles are obtained by solving the one-dimensional heat flow equation. Lateral thermal gradients are neglected because the processed diameter is much greater than the heating depth. Then, the heat flow equation to be solved is :

$$
\rho C(T) \frac{\partial T}{\partial t}=\frac{\partial}{\partial x}\left(\lambda(T) \frac{\partial T}{\partial x}\right)+Q(x, t)
$$

where $C(T)$ represents the specific heat per unit of volume and $\lambda(T)$ the thermal conductivity.

The temperature dependence of these parameters is taken into account in the calculation and variation laws were established starting from literature data. Numerical solution of equation (1) requires the use of boundary conditions which are imposed by the following physical considerations. Because of the short process time $(<h \mu s e c)$ radiation losses from the molten front surface are very weak and convection phenomena are negligible in the vacuum process chamber $\left(5 \times 10^{-6}\right.$ torr $)$.

In addition, the bulk of the wafer is assumed to be a thermostat at fixed temperature $\mathrm{T}_{\mathrm{o}}$

The phase change at the melting point is taken into account by condisering the equivalence between specific heat and latent heat. This model implies that the specific heat behaves like a Dirac function at the melting point. For the simulation a narrow gaussian singularity is used so that the enthalpy at any depth in the material can be simply memorized through the temperature. The same values have been used for the melt temperature of crystal or amorphous silicon. Equation (1) is digitized using three time and depth levels. This method described by Bonaccina et al./6/ is inconditionaly convergent. Moreover, it does not require iterations on the thermophysical data which are calculated on the intermediate time-level in order to obtain a differential equation with constant coefficients. The thermal data are taken in. theliterature $17,8,9 /$. The problem finally consists in solving the following matrix system at each time-step :

$$
\left(A_{i}\right)^{h, h-1}\left(T_{i}\right)^{h+1}=\left(E_{i}\right)^{h, h-1}
$$


where $i$ and $h$ are respectively the spatial and temporal integers. The matrix coefficients $A_{i}$ and $B_{i}$ depend only on time steps $h$ and $h-1$. By solving the system we obtain the temperature distribution $\left(T_{i}{ }^{h}\right.$ in the material at any time step $h$.

\section{PEBA INDUCED MELTING}

The PEBA thermal cycles include melting and freezing stage which can be described as follows: within the pulse duration a silicon surface layer is brought to the melt point. The melting layer thickness depends on the electron energy deposition profile which is rather penetrating unlike the energy deposition profiles of a laser.

Thus a particular feature of PEBA is to produce a deeper melting layer $(1 \mu \mathrm{m})$ than in the case of laser annealing $(0.3 \mu \mathrm{m})$ at the same fluence. However, the transient physical state of this melting layer depends on the absorbed latent heat fraction which is varying with depth as a function of both the crystal structure and the energy deposition profile.

Fig.l shows the enthalpy distribution after irradiation on silicon at $20^{\circ} \mathrm{C}$ as a function of the pulse energy deposition profile for the same superficial energy density $\left(1 \mathrm{~J} / \mathrm{cm}^{2}\right)$. The presence of an amorphous layer of thickness less than $0.4 \mathrm{\mu m}$ has no significant effect on the enthalpy distribution after irradiation because heat diffusion difference within the pulse duration is negligible. The energy gap between the top and the bottom horizontal doted lines corresponds to the latent heat $L_{c}$ for complete crystal silicon melting.

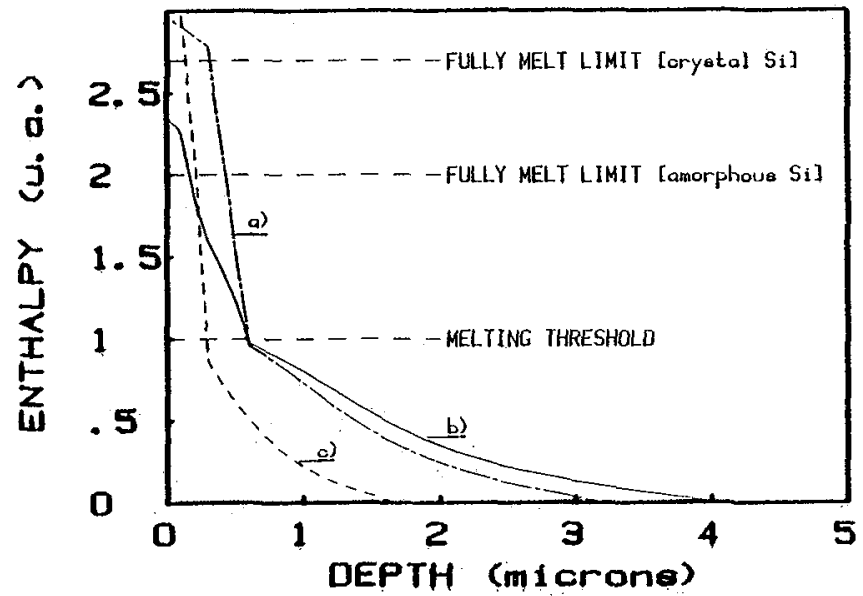

EIG 1: Enthalpy diatribution on $S i$ at $20^{\circ} \mathrm{C}$ after irradiation

a) $12 \mathrm{KeV}$ mean energy electron beam

b) $15 \mathrm{KeV}$ man energy electron beam Pulse: $1\left(\mathrm{~J} / \mathrm{cm}^{2}\right)$

In the case of a $12 \mathrm{keV}$ mean energy electron beam pulse (type a) on fig.1) crystal silicon is fully molten over $0.35 \mu \mathrm{m}$. In the case of a $15 \mathrm{keV}$ mean energy electron beam pulse (type b) on fig.1) one can see that the enthalpy required for complete melting of crystal silicon is not reached. Considering a $0.2 \mu \mathrm{m}$ thick fully amorphous layer with latent heat $\mathrm{L}_{\mathrm{a}} 40 \%$ lower than the crystal value $L_{\text {o }} / 7 /$, the fully melting enthalpy limit is lowered (medium horizontal line on fig.1). So that the type b) electron beam pulse induces an inhomogeneous physical state in the PEBA melting layer : the amorphous front layer is fully molten while a "melt like" state is achieved in the underlying crystal silicon over $0.44 \mathrm{~m}$. Whith the type a) electron beam pulse the non fully molten layer thickness is less than of the computer simulation depht-step. Moreover the fully molten layer extends beyond the amorphous layer. In that case, the problem of melt temperature difference between crystal and amorphous silicon is eliminated $/ 10 /$, while it should be taken into account for a type b) electron beam pulse. It must be noted that the above described features remain unchanged in the 0.7 to $1.4 \mathrm{~J} / \mathrm{cm}^{2}$ fluence range. 
The enthalpy profile induced by a pulsed laser is also plotted on type c) fig.1. This profile is very similar to a type a) electron beam pulse but the fully molten layer thickness is deeper for the electron beam pulse than for the laser pulse.

\section{EFFECT OF SAMPLE STARTING TEMPERATURE ON THE FREEZING KINETICS}

Computer simulations of the PEBA induced temperature profiles have been performed either with a $20^{\circ} \mathrm{C}$ or a $450^{\circ} \mathrm{C}$ starting temperature. Fig. 2 shows the melting layer thickness evolution versus fluence for the type a) electron beam pulse.

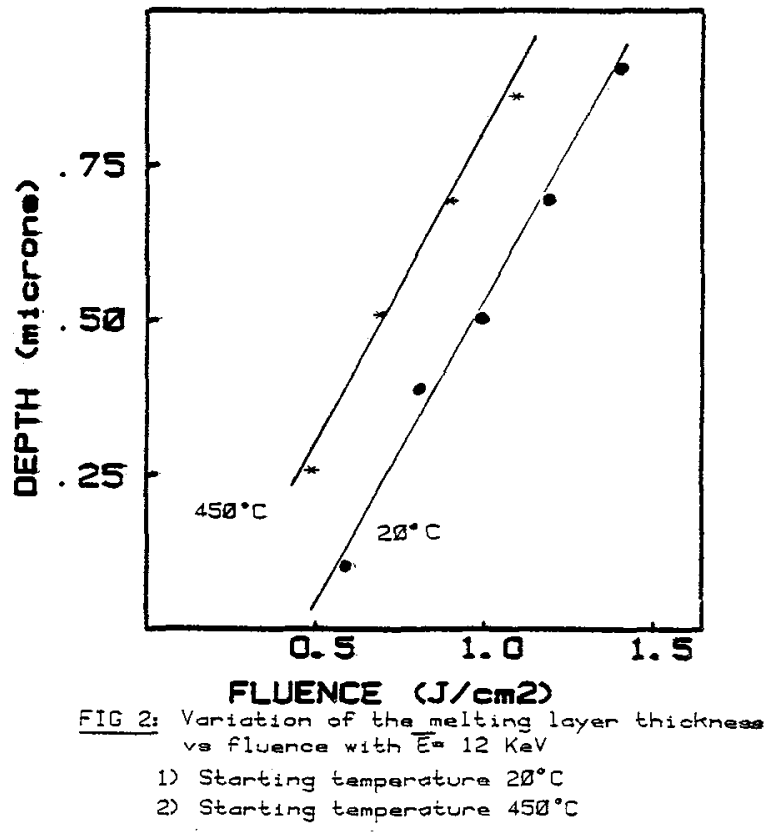

The effects of heating silicon before pulsing only consists in an constant increase of the induced melting layer thickness whatever the fluence value. In the case of a type b) electron beam pulse the region where a "melt like" state is achieved undergoes the same shift as the melting layer as compared to the effects obtained with a $20^{\circ} \mathrm{C}$ starting temperature. During the freezing process the energy absorbed in the melting layer is released by thermal conduction through the bulk of the material. The freezing kinetic is then controlled by the dissipation rate of the latent heat which mostly depends on the depth distribution of thermal gradients in the solid beneath the melting layer. The melting solid interface velocity $\mathrm{V}_{\mathrm{s}}$ is given by :

$$
\eta\left(\mathrm{X}_{M}\right) \text { L } \rho \mathrm{V}_{\mathrm{s}}=\lambda\left(\frac{\mathrm{dT}}{\mathrm{dx}}\right)_{\mathrm{X}}
$$

where $\bar{\eta}\left(\mathrm{X}_{\mathrm{M}}{ }^{\mathrm{L}}\right.$ is the latent heat fraction (between 0 and $\mathrm{L}$ ) to be evacuated at the melting-solid interface of abscissa $X_{M}, \lambda$ the thermal conductivity and $(d T / d x)_{X_{M}}$ the thermal gradient at depth $\mathrm{X}_{M}$ inside the solid region.

On fig. 3 are plotted the mean melting-solid interface velocity $V_{s}$ as a function of fluence for a type a) electron beam pulse as deduced from computer simulation using a $20^{\circ} \mathrm{C}$ and $450^{\circ} \mathrm{C}$ starting temperature.

At $1 \mathrm{~J} / \mathrm{cm}^{2}$, the interface velocity is nearly constant for a $20^{\circ} \mathrm{C}$ starting temperature. The strong variation below $1 \mathrm{~J} / \mathrm{cm}^{2}$ is related to non-complete silicon melting $(\eta<1)$. Effect of heating silicon to $450^{\circ} \mathrm{C}$ consists in a division by two of the melting-solid interface velocity $(2 \mathrm{~m} / \mathrm{s}$ to $1 \mathrm{~m} / \mathrm{s})$. According to equation 3 , this effect is consistent with the decrease of the thermal gradient $(\mathrm{dT} / \mathrm{dx})_{X_{M}}$ from about $500 \% \mu \mathrm{m}$ to $350 \% \mu \mathrm{m}$. 


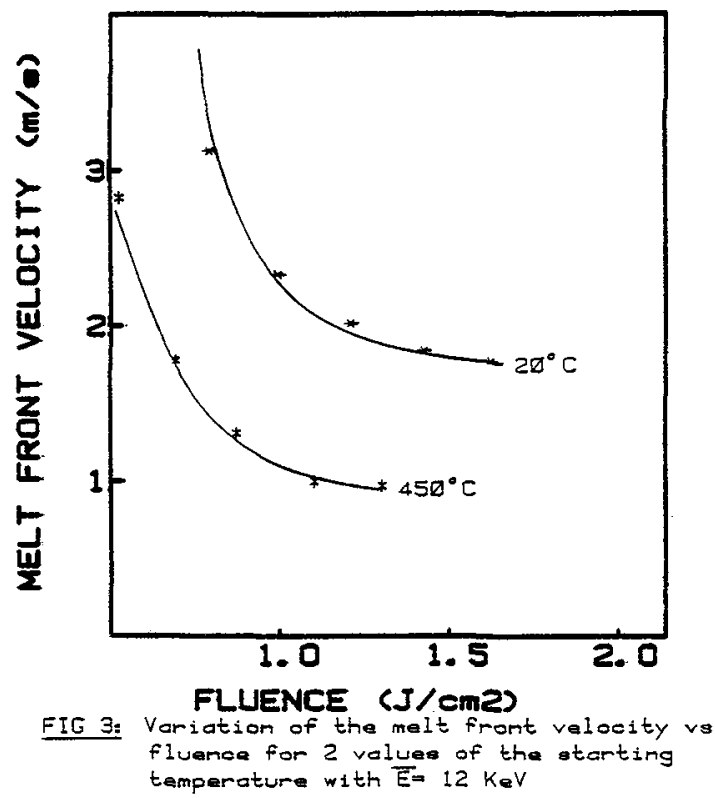

\section{REMARKS AND CONCLUSION}

Because of a rather penetrating energy deposition profile PEBA induces a deeper melting layer in silicon than pulsed lasers. However, the physical state of this melting layer is controlled by the energy deposition profile and also depends on the crystal structure of the surface layer. The effect of heating silicon up to $450^{\circ} \mathrm{C}$ is to increase the melting layer thickness and to reduce the melting-solid interface velocity by the same factor as the thermal gradient inside the solid region. Consequently heat release from the surface is slowed down so that after resolidification the silicon surface temperature stays higher than $800^{\circ} \mathrm{C}$ a longer time than when using a $20^{\circ} \mathrm{C}$ starting temperature. We believe that this cooling rate reduction should be equivalent to a post-PEBA thermal annealing at high temperature as suggested by the decrease of the defect concentration in the regrowth layer when PEBA is performed on silicon heated above $400^{\circ} \mathrm{C} / 11 /$.

\section{REFERENCES}

/1/ WHITE C.W., NARAYAN J., YOUNG R.T., M.R.S. Proceed.AIP 50 New York (1979) 175

12/ GREENWALD A.C., KIRKPATRICK A.R., LITTLE R.G., MINNUCCI J.A., J.Appl.Phys. $\underline{50}$, 2 (1979) 783

13/ WHITE C.W., NARAYAN J., YOUNG R.T., M.R.S. Proceed. AIP 50 New York (1979) 275

14/ LAUGIER A., BARBIER D., CHEMISKY G., Proceed. of 4th E.C. Photovoltaic Conf. Reidel edit. (1982) 1007

15/ BARBIER D., BAGHDADI M., LAUGIER A., VICARIO E., J.Microsc.Spectrosc.Electr. 6 (1981) 513

16/ BONACCINA C., COMINI G., FASANO A., PRIMICERO M., Intern. Journal of Heat Mass Transfer, 16 (1973) 1825

17/. BAERI P., FOTI G., POATE J.M., CULLIS A.G., Phys.Rev.Lett. 45, 25 (1980) 2036

181 MAYCOCK P.D., Sold.Stat.Electr. 10 (1967) 161

19/ SHASHKOV Y.M., GRISHIN V.P., Sov.Phys.Sol.State 8, 2 (1966) 447

/10/ RIMINI E., BAERI P., CAMPISANO S.U., FOTI G., M.R.S.Proceed. AIP 50, New York (1979) 259

/11/ LAUGIER A., BARBIER D., DOGHMANE M.S., CHEMISKY G., this conference 